Hand Clin. 2014 May ; 30(2): 137-151. doi:10.1016/j.hcl.2013.12.004.

\title{
Local Flaps of The Hand
}

\author{
Shady A. Rehim, MB ChB, MSc ${ }^{1}$ and Kevin C. Chung, MD, MS ${ }^{2}$ \\ ${ }^{1}$ International Research Fellow, Section of Plastic Surgery, Department of Surgery, University of \\ Michigan Health System, Ann Arbor, Michigan \\ 2 Professor of Surgery, Section of Plastic Surgery, Assistant Dean for Faculty Affairs, University \\ of Michigan Medical School, Ann Arbor, Michigan
}

\section{Synopsis}

A local flap consists of skin and subcutaneous tissue that is harvested from a site nearby a given defect while maintaining its intrinsic blood supply. When a soft tissue defect of the hand is not amenable to primary closure or skin grafting, local skin flaps can be a used as a reliable source of soft tissue replacement that replaces like with like. Flaps are categorized based on their composition, method of transfer, flap design and blood supply, yet flap circulation is considered the most critical factor for the flap survival. This article reviews the classification of local skin flaps of the hand and offers a practical reconstructive approach for several soft tissue defects of the hand and digits.

\section{Keywords}

Hand flaps; Soft-tissue coverage; Reconstruction

\section{Introduction}

The hand is an intricate part of the body that plays an essential role in social functioning, expression, productivity, and interactions with our environment. ${ }^{1}$ Skin/soft-tissue envelope of the hand is a complex structure that not only covers the underlying structures but also has specialized functional and sensory components. The thick glabrous skin of the palm withstands shearing forces encountered during daily activities and provides discriminatory sensory function that transfers touch, pain and temperature, whereas the dorsal skin is pliable and mobile that permits a wide range of motion of the hand such as fingers pinch and grip. ${ }^{1-2}$ Soft-tissue defects of the hand following trauma or tumor resection are frequently

\footnotetext{
(C) 2013 Elsevier Inc. All rights reserved.
}

Corresponding Author: Kevin C. Chung, MD, MS Section of Plastic Surgery University of Michigan Health System 2130 Taubman Center, SPC 53401500 E. Medical Center Drive Ann Arbor, MI, 48109-5340 kecchung@umich.edu Phone 734-936-5885 Fax 734-763-5354.

Publisher's Disclaimer: This is a PDF file of an unedited manuscript that has been accepted for publication. As a service to our customers we are providing this early version of the manuscript. The manuscript will undergo copyediting, typesetting, and review of the resulting proof before it is published in its final citable form. Please note that during the production process errors may be discovered which could affect the content, and all legal disclaimers that apply to the journal pertain.

Disclosure: None of the authors has a financial interest in any of the products, devices, or drugs mentioned in this manuscript. 
encountered in hand surgery and may result in a temporary or permanent disability if not managed appropriately.

Over the past decades, several reconstructive procedures and their modifications have evolved to provide the ideal soft tissue coverage of the hand. ${ }^{3}$ Conventionally, these included a range of options of primary wounds closure, skin grafts, local flaps, distant flaps, and micro-vascular free tissue transfer. ${ }^{3-6}$ However, selecting the most suitable type of soft tissue cover for a particular defect can be a challenging process. Furthermore, the abundance of currently available reconstructive techniques makes this task rather difficult, especially for the in experienced surgeon. When choosing one reconstructive method over the other, it is prudent that the surgeon have a sound knowledge of all available options, their limitations, complications and expected outcomes. Reconstruction algorithms such as the reconstructive ladder, reconstructive elevator and reconstructive matrix have been devised to assist surgeons in determining the most appropriate type of soft-tissue reconstruction. ${ }^{7-8}$ Although sometimes useful, there is no simple schema for reconstruction as every injury is different and every patient has a unique set of medical conditions. This practical guide offers an overview of several types of local hand flaps. With these flaps the majority of small-tomedium sized defects of the fingers, thumb and dorsum of the hand can be reconstructed with minimal donor site morbidity and excellent functional and aesthetic results because a tissue defect is replaced with similar tissue type from the immediate anatomic vicinity of the defect.

\section{General Considerations}

A careful patient history and mechanism of the injury are indispensible in assessing the potential structural involvement and previous interventions. This provides a framework in which to begin treatment. It is clear that one of the most influential factors in consideration of any treatment is tissue loss, including defect size, site, depth, orientation and composition. However other factors such as those related to patients and surgeons' technical ability as well as the availability of resources is of an equal importance (Table 1). A systematic evaluation of all these factors is essential to individualize the reconstruction plan to each patient.

When closure of skin defects of the hand cannot be obtained by simple methods such as healing by secondary intention or primary closure, other methods should be employed. Skin grafts require a vascularized wound bed for the graft to take and are not suitable to cover defects over exposed tendons or bones without paratenon or periosteoum. Furthermore the high contracture potential, limited scar pliability, and poor sensibility limit their successful use as a primary method of reconstruction in the hand. ${ }^{5}$ Locoregional or free tissue transfers bring their own blood supply, thus have been frequently used to cover complex injuries with exposed tendons and bones. However contemplating between local flaps (harvested from adjacent tissue) or flaps (harvested from distant anatomic sites), several factors need to be considered. First, the simplest procedure that provides adequate amount of tissue coverage and result in maximal gain of function together with the least amount of donor site deformity should be selected. Second, whenever possible, tissue replacement should follow the principle of replacing like with like to provide good color, texture, hairiness and volume 
match. ${ }^{8-9}$ Different regions of the hand have different functional and aesthetic requirements. For example, reconstructing highly sensate areas such as the fingertips with non-sensate skin may cripple the entire function of a patient's hand. On the other hand, transposing skin containing hair follicles to a hairless surface such as the palm would result in poor aesthetic appearance and patient dissatisfaction with surgery. Because the surgeon must consider function when addressing the appearance of the hand, we have coined the term 'functional aesthetic units and subunits' of the hand. These units and subunits divide the hand into distinct regions after taking into consideration the unique functional and aesthetic properties of each specific region.

If there are no specific contraindications for local skin flaps such as crush injuries or the presence of local infection, they should be considered as the first line of treatment. ${ }^{9}$ In addition to replacing like with like, the use of local skin flaps avoids the need for skin grafts or more extensive procedures such as free flaps. In all the following flap descriptions below, we assume that other reconstructive options apart from local flaps have been weighed and rejected.

\section{Classification of Skin Flaps}

A flap is skin with a varying amount of underlying tissue that is used to cover a defect and receives its blood supply from a source other than the tissue on which it is transferred to. ${ }^{10-11}$ Skin flaps can be classified according to their method of transfer (e.g. advancement, rotation, and transposition) ${ }^{11}$, composition (e.g. cutaneous, fasciocutaneous, fascial, adipofascial or compound flaps including bone and/or tendon) ${ }^{12}$ and geometric design (e.g. rhomboid, bilobed etc.). If classified according to their location in relation to the defect alone, they can be grouped into 3 types of flaps ${ }^{9}$ :

Local flaps: Harvested from the injured digit or tissue surrounding injured zone of the hand.

Regional flaps: Harvested from adjacent non-injured digit or zone of the hand.

Distant flaps: Harvested away from the injured hand.

If local skin flaps are further divided according to their blood supply, they can be grouped into random or axial pattern flaps as shown by McGregor in 1972. ${ }^{13-14}$

\section{- Random pattern flaps:}

Random pattern flaps have no known feeding blood vessel. Instead they are supplied by a random pattern of subdermal plexus and hence their name random pattern flaps. Because they lack a known vascular pedicle, the flap size is usually limited to a length-to-width ratio of 1:1 because of the limits of the perfusion pressure. However this general rule does not strictly apply in highly vascularized areas such as the face or hands, in which a flap can be carefully extended to increase the flap length in respect to width in these areas. Examples of random pattern skin flaps include; Rotation, rhomboid and transposition flaps.

\section{Axial pattern flaps:}


Axial pattern flaps are based on a known artery that directly supplies a specific skin territory. Interconnections between branches of adjacent axial vessels exist that connects neighboring skin territories. Behan and Wilson were first to describe a system of linked axial pattern flaps via vascular communications based on a known arterial supply that was termed angiotome ${ }^{15}$ Taylor and colleagues later emphasized the role of these interconnections (choke vessels) and stated that when a flap is based on vessels of one angiosome, the corresponding tissue of adjacent angiosome can be safely captured based on the blood supply of the first angiosome. ${ }^{16-17}$ Thus in contrast to random pattern flaps, axial flaps may be extended beyond the 1:1 ratio to cover larger defects owing to their more robust blood supply because the axial vessel provides a much larger perfusion territory.

An axial pattern flap can also be traced along its vascular pedicle thus converted to an island pedicled flap. This permits a greater freedom of mobility and increases the span of the flap to reach more distant defects. Although this can be sometimes advantageous, kinking or avulsion of the vascular pedicle jeopardizes the viability of the whole flap. Examples of axial pattern flaps include; Thumb neurovascular advancement flap (Moberg), first dorsal metacarpal artery flap, second dorsal metacarpal artery flaps, among others.

\section{Local flaps for Dorsum of The Hand}

Random pattern flaps such as rotation or transposition flaps are useful local skin flaps for coverage of a variety of soft tissue defects over the dorsal surface of the hand. By taking an advantage of the skin laxity together with carefully measured geometric flap designs, one can successfully move tissue around to close several skin defects. Furthermore if used correctly, random pattern flaps can be applied throughout the hand and fingers. As a rule, one should always perform finger pinch test to decide which adjacent area provides most soft tissue for closure with respect to relaxed skin tension lines when executing these flaps so the donor site can be closed directly.

\section{The Rotation Flap}

The name rotation flap refers to the vector of movement of the flap, which is usually curved or rotational. This flap can be thought of as the closure of a triangular defect by rotating adjacent skin around a rotation point (or fulcrum) into the defect ${ }^{18}$ (Fig. 1A-C). After outlining the defect, the arc of flap rotation should be designed at least 3-4 times larger the diameter of the defect to allow sufficient rotation of the flap and closure without excessive tension. A common mistake is to design a flap that is too small and cannot be sufficiently rotated into the defect. In these instances a small back cut or creation of a Burow's triangle can help gain extra rotation. However, nothing is worse than a poorly designed flap and despite these maneuvers frequently the flap cannot be sufficiently mobilized and create a secondary defect from the donor site. The temptation to extend the back cut in order to gain further length may jeopardize the viability of the flap as it cuts through the blood supply at the base of the flap. It is therefore advisable to design the flap relatively large from the outset to avoid this situation. 


\section{The Rhomboid/Limberg Flap}

First described by Limberg in 1928, the rhomboid flap is a transposition flap that consists of an equilateral parallelogram with two angles of $120^{\circ}$ and two of $60^{\circ} .{ }^{19}$ To execute this flap, first the defect is converted into a rhomboid. A line is extended that equals the height of the rhomboid. This line is then extended parallel to one side of the rhomboid (Fig. 2A). The flap is elevated and transposed into defect while the secondary defect is closed directly. In actual practice defects have different sizes, shapes and orientation. Strictly adhering to the above described measurements/angles may not provide the best aesthetic appearance. As the surgeon gains cumulative experience with performing these flaps, the flap design can be slightly modified to better fit the defect. For example, the margins of the defect as well as the transposed skin of the rhomboid flap can be rounded/curved in a similar fashion to the bilobed flap. This maneuver eliminates the pointed triangular edges of the flap that can be strangulated by tight skin closure during flap inset (Fig. 2B). Furthermore, when designing the rhomboid flap on the dorsum of the hand, one must be mindful that the line of closure of the secondary defect lies in parallel to relaxed skin tension lines to avoid puckering of the skin and achieve skin closure without excessive tension.

\section{Fingers}

It is easier to consider reconstruction of finger injuries if we divide the fingers into three parts; distal to the proximal interphalangeal (PIP) joint, at the level of PIP joint and proximal phalanx. In addition to the level of injury, the side of injury should also be considered. Defects over palmar and dorsal surfaces of the fingers require different reconstruction options, as follows.

\section{The V-Y Advancement Flap}

The V-Y advancement flap was first described by Tranquilli-Laeli in 1935 but was popularized by Atasoy and colleagues in the United States in 1970. ${ }^{20-21}$ Fingertip amputation is a common injury that frequently results in soft tissue defects with an exposed underlying bone of the distal phalanx that cannot be left to heal with secondary intention or covered by skin grafts. The availability of remaining adjacent soft tissue and the pattern of injury usually dictates the method of treatment. The V-Y advancement flap is most suitable for coverage of transverse or dorsal oblique fingertip amputations with exposed bone and sufficient nail bed support and length. ${ }^{22}$ Additionally, the V-Y advancement flap can be used to resurface adherent sensitive scars over fingertips resulting from previous amputation injuries. This flap provides excellent soft tissue replacement in terms of skin color, texture, sensation and padding. However, in volar oblique fingertip amputations other options should be considered.

The V-Y advancement flap incorporates the volar digital neurovascular bundles that provide vascular and sensory supply to the flap. The first step of executing this flap includes marking the boundaries of the V-Y flap by drawing an inverted ' $\mathrm{V}$ ' on the volar side of the distal phalanx (Fig. 3A). The apex of the flap extends proximal towards the level of the distal interphalangeal (DIP) joint crease while the base extends distally to the radial and ulnar borders of the amputated nail bed. Extension of the skin incision beyond the DIP joint 
flexural crease should be avoided as this may result in the development of skin contracture and flexion deformity of the distal phalanx. On the other hand extending skin incisions laterally beyond the borders of the nail bed may result in a flattened appearance of the nail bed. A combination of sharp and micro-scissors dissection is used to raise the flap. On either ends of the base of the flap, full-thickness skin incisions are performed that extend all the way down to the periosteum to free periosteal attachments of the flap whilst preserving nourishing digital vessels. Towards the center, the flap is dissected off the flexor tendon sheath by carefully passing the tip and body of the scalpel from distal to proximal to the deep margin of the flap to cut through fibro-fatty subcutaneous tissue to aid mobilization of the flap (Fig. 3A). Once the flap is freed from its attachments, a skin hook is used to gently pull the distal end and advance the flap it into the defect (Fig. 3 B-C). At this point, it should be emphasized that most of published textbook illustrations of the V-Y flap put the reader under the impression that the flap can be easily advanced forward. However, one must appreciate that V-Y advancement flap has a relatively limited mobility and only about $0.5 \mathrm{~cm}-1 \mathrm{~cm}$ of advancement can be obtained, that limits the use of this flap to a relatively small-sized fingertip defects. After flap advancement, the proximal wound is closed as a ' $\mathrm{Y}$ ', hence the name V-Y advancement flap. The tourniquet is released to check perfusion of the flap and the distal end is sutured without excessive tension (Fig. 4).

\section{The Thenar Flap}

Gatewood first described the technique of a thenar flap for coverage of fingertip injuries in $1926 .{ }^{23}$ Subsequently this was expanded upon by Flatt in $1957 .{ }^{24-25}$ The thenar flap is indicated for volar skin avulsions over the pulp of the finger (e.g. volar oblique amputations); however, its use can also be extended to cover dorsal defects over the nail bed. Advantages of the thenar flap includes inconspicuous donor site defect and good softtissue padding, color and texture match from the glabrous skin over the thenar area to the pulp of the finger. The major disadvantage of this flap is the propensity of PIP joint contracture and finger stiffness. Young women and children tend to have more supple joints and are therefore good candidates for the thenar flap.

The site of the donor site is identified by gently flexing the fingers towards the thenar eminence. The area of contact between the finger pulp and thenar eminence is the correct site of the donor site that because of individual variation usually lies at or just proximal to the level of thumb metacarpophalangeal (MCP) joint. Excessive flexion of the finger will result in marking a donor site too proximal on the palm that eventually results in excessive tension on the flap and may jeopardize the success of the whole procedure. Once the correct donor site is identified, a rhomboid shaped flap is designed, alternatively a circular or an Hshaped flap can be designed based on the shape and size of the finger defect (Fig. 5-6). The flap size should be made slightly larger than the size of the defect. A full-thickness skin flap is then raised at the level of thenar muscle fascia. Care must be taken not to injure the radial digital nerve of the thumb that usually lies anterior to the midaxial lines of the thumb. Once the flap is elevated the injured finger is advanced into the raw area to encompass the distal pulp space. The end of the flap is sutured to the defect and the donor site is closed primarily. The tourniquet is released to check the flap viability. The finger is left attached and after 2-3 
weeks the flap is divided thus replacing the original soft-tissue defect with glabrous matching skin.

\section{The Cross-Finger flap}

The cross-finger flap is a two-staged flap reconstruction that was first described by Cronin $1951 .{ }^{26}$ Volar soft tissue defects located on the middle or distal phalanx can be covered with this flap. Another indication of the cross-finger flap is for more distal defects in which more tissue is required for coverage than what can be obtained from a local advancement flap such as V-Y flap. Akin to thenar flap, PIP joint stiffness due to joint flexion and immobilization is of a concern when using the cross-finger flap.

The middle finger can be used to repair defects on either adjacent index or ring fingers, otherwise the donor finger is the one radial to the injured finger. The flap is outlined and elevated in an open book fashion in which a 3-sided rectangular or a rhomboidal shaped flap is outlined on the dorsum of the middle phalanx of the healthy digit. The fourth side of the rectangular flap acts as the hinge of the flap located at the midaxial line of the finger nearest to the injured digit. A pattern can be used and transposed onto the donor-site to estimate the size of the flap required. The flap should be designed slightly larger than the actual defect to avoid closure with excessive tension. A full-thickness skin flap is then raised over the paratenon of the underlying extensor tendon (Fig. 7-8). Care must be taken not to strip-off the paratenon so that the secondary defect can be closed with a skin graft. After flap elevation, the flap is rotated 180 degrees around its hinge and secured over the palmar defect of the adjacent injured finger. A full-thickness skin graft is then harvested to close the secondary defect. A krishner wire can be used to stabilize the fingers together to avoid pulling or detachment of the flap, but this is not necessary in the authors' experience. The fingers are immobilized for approximately 2-3 weeks after which a secondary procedure is performed to divide the skin bridge.

Pakian ${ }^{27}$ first used a modification of the cross-finger flap known as the reverse cross-finger flap for defects located on the dorsal side of the fingers. In principle the reverse cross-finger flap is similar to the classic cross-finger flap, however the technique is slightly different. The flap is designed within the functional limits of the phalanx on the dorsal aspect of the adjacent non-injured finger. A cross-finger flap should not be harvested from the volar side of the finger as this will lead to volar scar contracture and will leave major donor site problem. The same open book technique of raising a 3-sided rectangle with the fourth side acting as a hinge adjacent to the injured finger is used. The skin is raised at the level of the deep dermis leaving behind the rest of the deep layer of dermis and subcutaneous tissue. This in turn is raised in the same manner over the paratenon and reflected 180 degrees to cover the primary defect. By doing so the superficial surface of the subcutaneous flap lies directly on the wound bed of the primary defect while its deep surface becomes superficial that is subsequently covered with a full-thickness skin graft (Fig. 9). The skin flap that was initially raised from the donor-site is then reflected back to cover the secondary defect. After a period of 2-3weeks the bridge of the subcutaneous flap can be safely divided. 


\section{The Homodigital Island flap}

Weeks and Wray in 1973 described the homodigital island flap that is based on the volar blood supply of the fingers, either the radial or ulnar digital artery and its venae comitantes. ${ }^{28}$ The flap can be harvested on a proximal (antegrade) or a distal (retrograde) pedicle. ${ }^{29}$ Proximally based flaps are used to cover more proximal defects, whereas reverse pedicle digital island flap described by Lai and colleagues ${ }^{30}$ are used to cover more distal defects over PIP and DIP joints (Fig. 10). Contrary to cross-finger flap, the advantages of this flap include a single-staged procedure that is confined to the injured digit. However, hand surgeons are currently less enthusiastic to perform this flap due to fine dissections and increased risk of damage of the vascular pedicle as well as decrease of sensation over the donor site especially in dominant fingers. Furthermore, this flap is not suitable for patients with peripheral vascular disease or in digits nourished by a single vessel. A positive digital Allen's test showing incomplete collateral perfusion is therefore a contraindication to the use of this flap. ${ }^{20}$

For the reverse pedicle digital island flap, the flap is outlined on the lateral border of the base of the affected digit. A pattern is used and transferred onto the donor area to estimate the size of the flap required. In general, the flap should always be designed slightly larger than the actual defect to account for primary skin contraction. Dissection is carried out from proximal to distal until enough length of the pedicle is obtained, which usually corresponds the level of the DIP joint. During dissection the digital nerve is gently separated from the vascular pedicle and the digital vessel is ligated proximally. The pedicle should be raised with a cuff of fat, attempts to skeletonize the pedicle may result in damage of the venous drainage or vascular supply of the flap. Once the island flap elevated, it is rotated into the defect and sutured loosely to avoid compression of the pedicle. A full-thickness skin graft is then harvested to close the secondary defect.

\section{The Dorsal metacarpal artery flap}

In 1987, Earley and Milner first described the proximally based dorsal metacarpal artery flap based on the first and second dorsal metacarpal artery. ${ }^{31}$ In 1990, Quaba and Davison ${ }^{32}$ introduced another subset of flaps called the distally based dorsal metacarpal artery (DMCA) flap that is not based on the dorsal metacarpal arteries, but rather on a constant palmar-dorsal perforator present in the digital web-space (Figure 11. The DMCA flap became a popular flap for coverage of dorsal finger defects up to the level of the PIP joint. Several flap modifications have been devised since based on the vascular anatomy of the DMCA and the more distal dorso-palmar digital cutaneous perforators in order to increase the span of the flap to reach more distal defects. ${ }^{33-37}$

The DMCA flap is indicated for large dorsal finger defects or when a one-stage procedure is preferred to allow finger mobilization. The flap can also be used to reconstruct volar defects over the proximal, however this should be discouraged as the transposition of hairy pigmented skin from the dorsal surface of the hand is not an ideal match to the glabrous, lighter-colored skin of the palmar surface of the fingers especially in dark skinned individuals. 
The flap is usually centered on location of the palmar-dorsal perforator of deep palmar arch. The boundaries of the flap extends between the distal edge of the extensor retinaculum proximally and the MCP joint distally and the outer borders of the adjoining metacarpals on either side. ${ }^{38}$ The flap is harvested from proximal to distal, raising the skin flap above the paratenon of the underlying extensor tendon. The pedicle is traced along the course of the perforator that usually arises immediately distal to the juncturae tendinum at the interdigital space. One must not attempt to isolate the perforator as this may lead to its damage and affect flap viability. At this point the tourniquet is released to check flap perfusion. The flap is then rotated and passed through a subcutaneous tunnel to reach the defect (Fig. 12A-B \& Fig. 13). The primary defect is closed by primary closure and the fingers and wrist are immobilized in extension.

The DMCA flap can be modified to reach more distant defects over the dorsum of the middle/distal phalanx. This may involve designing the flap as a curved ellipse instead of a straight ellipse. After raising the flap, straightening the curved skin ellipse during flap inset offers additional 8-10mm length (Fig. 14). Another maneuver involves dividing and ligating the dorsal metacarpal artery proximal to the perforator. Since a perforator arising from the deep palmar arch directly nourishes this flap, its attachment with dorsal metacarpal artery can be carefully divided to allow a greater advancement of the flap. ${ }^{38}$

\section{Thumb}

The thumb represents $40-50 \%$ of hand function. ${ }^{39}$. Restoring thumb defects is essential for pulp-to-pulp and key pinch grip. The arterial supply of the thumb differs greatly from that of other fingers. The volar side of the thumb is supplied by two palmar collateral arteries arising from the princips pollicis artery that in turn is derived from the radial artery at the first intermetacarpal web-space. ${ }^{40}$ The dorsal blood supply of the thumb is fairly independent from its volar circulation. The skin over the dorsum of the thumb is predominantly supplied by ulnar dorsocollateral and radial dorsocollateral arteries, branches of the radial artery. Based on knowledge of the anatomical blood supply of the thumb several local flaps can be elevated to reconstruct volar and dorsal defects, as follows.

\section{The Moberg Flap}

The advancement neurovascular flap of the thumb was originally described by the Erik Moberg in 1964 hence it is best known today as the Moberg flap. ${ }^{41}$ The Moberg flap is indicated for coverage of small-to-medium sized defects over the volar aspect of the distal phalanx of the thumb without the need of shortening length. This flap provides excellent soft-tissue coverage with highly sensate, well-padded skin of similar color and texture. The main disadvantage of the Moberg flap is tendency for interphalangeal (IP) joint flexion deformity, if the flap is insufficiently mobilized to cover volar distal defect.

The flap is outlined along midaxial lines on either sides of the thumb. The proximal border of the flap should correspond to level of flexural crease of the MCP joint. At the distal end of the flap, a full-thickness skin incision is made along the midaxial lines. Care must be taken not to sever the neurovascular bundles nourishing the flap that lie just anterior to the mid axial crease (Fig. 15). The flap is gently dissected off the flexor pollicis longus tendon 
incorporating digital vessels and nerves. Once the flap is freed from all but its proximal attachment, the flap can be advanced $1-1.5 \mathrm{~cm}$ towards the distal end and sutured to the tip of the thumb to cover the defect without excessive tension. Often the flap cannot be advanced enough to cover the entire defect. In these instances minimal trimming of the distal phalanx can be performed. Alternatively the IP joint can be slightly flexed. However in order to preserve the entire length of the thumb and prevent flexion deformity of the IP joint, the proximal end of the flap can be modified to extend across the MCP flexural crease as a Vshaped incision converting the flap into an island flap to gain further length. After advancing the flap the proximal wound is closed in a V-Y fashion. Another type of flap modification involves making a proximal transverse incision along the MCP joint crease again this converts the flap into an island flap. However the resultant skin defect is not directly closed, alternatively is covered with a full-thickness skin graft to avoid the development of vertical skin contractures across the MCP joint. When executing these modifications one must be cautious to preserve the neurovascular bundles and should only be performed when necessary.

\section{The First dorsal metacarpal artery flap-FDMA (Kite flap)}

Foucher and Braun in 1979 described the first dorsal metacarpal artery flap also known as the kite flap because the flap is raised with the pedicle, which resembles a kite. ${ }^{42}$ The kite flap is a skin island flap harvested from the dorsal surface of the adjacent index finger. The constant first dorsal metacarpal artery, a branch of the radial artery, nourishes the flap. The flap may also incorporate a branch of the superficial radial nerve. This makes the kite flap a good choice for reconstructing all dorsal defects of the thumb and can be used to restore sensibility over thumb pulp defects in a single staged procedure. The disadvantages of this flap may include creating a conspicuous donor-site defect that is closed with a skin graft. Furthermore when reconstructing the pulp of the thumb, the relatively darker dorsal skin containing hair follicles may produce a less aesthetically pleasing result.

Execution of the kite flap involves outlining the boundaries on the dorsal surface of the proximal phalanx of index finger. A full-thickness skin incision is then performed and the flap is dissected from distal to proximal. The flap is elevated together with the underlying fascia of the first interosseus muscle incorporating the vascular pedicle that runs deep in overlying fascial pocket. The pedicle is harvested with a cuff of subcutaneous tissue and no efforts should be made to identify or isolate the pedicle as this may damage its blood supply. The pedicle is then traced back to a point near its base at the anatomic snuff-box that contain the radial artery to allow rotation of the flap. Once the flap and the pedicle are dissected, the perfusion of the flap is checked by temporary deflating the tourniquet. A subcutaneous tunnel is then created in order to place the flap through the tunnel and into the thumb defect. The subcutaneous tunnel must be spacious enough not to exert any pressure on the pedicle. Alternatively, a skin paddle is harvested over the pedicle which can be transposed along the path of the flap to the defect. This is our preferred flap design to avoid passing the flap through the tunnel that can kink the pedicle (Fig. 16A-B). The donor defect is usually closed by a full-thickness graft. 


\section{The Dorsoulnar and Dorsoradial Collateral Artery Flaps}

The reverse flow homodigital dorsoulnar and dorsoradial collateral artery flaps (Fig. 17) were described by Brunelli (1993) ${ }^{43-45}$ and Moschella (2006) ${ }^{46-47}$, respectively. These flaps are supplied by the ulnar dorsocollateral and radial dorsocollateral arteries that arise from the radial artery at the level of the head of the first metacarpal bone and run on their respective sides to supply the skin over the dorsum of the thumb. Studies have shown the constancy of these vessels, however a Doppler examination helps to identify the course of the vessel and to mark the pivot point of the flap. ${ }^{29}$ The advantages of using these flaps is two fold. First the donor site is confined to the thumb and in most cases can be closed primarily thus leaving inconspicuous scars. Second, the dorsocollateral branch of the superficial radial nerve can be harvested with the flap and reconnected to one of the volar collateral nerves of the thumb to create a sensate flap to reconstruct defects over the pulp of the thumb. The disadvantage associated with these flaps is the need for delicate microdissection, a process that has been described as microsurgery without anastomosis.

The two flaps, dorsoulnar and dorsoradial reverse flow collateral artery flaps are elevated in a similar fashion. First the skin flap is centered on the feeding blood vessel either on the dorsoulnar or dorsoradial sides of the dorsum of the thumb, based on type of flap to be executed. Flap dissection is carried out from proximal to distal to avoid damaging the pedicle. One should always avoid isolating the pedicle. Dissection of the flap is continued to the level at middle of the proximal phalanx to preserve the anastomosis between palmar and dorsal vessels. At this point the tourniquet is deflated to check perfusion of the flap. The flap is then reflected and secured to the defect taking care not to compress the pedicle. A cutaneous tail should be harvested to avoid tunneling of the flap, and to allow for primary skin closure after rotation of the flap into the defect. ${ }^{48}$

\section{Summary}

Where there are no clinical restrictions, local flaps represent an ideal soft tissue cover for small and moderate soft-tissue defects. A surgeon who is well versed with the vascular anatomy of the hand and different types of local flap reconstruction will be able to treat a variety of defects without resolving to more complex methods of soft tissue repair. Nonetheless, one must also recognize the limitations of local flaps and be prepared to change treatment plan if the necessity arises.

\section{Acknowledgments}

Supported in part by grants from the National Institute of Arthritis and Musculoskeletal and Skin Diseases and National Institute on Aging (R01 AR062066) and from the National Institute of Arthritis and Musculoskeletal and Skin Diseases (2R01 AR047328-06) and a Midcareer Investigator Award in Patient-Oriented Research (K24 AR053120) (to Dr. Kevin C. Chung).

\section{References}

1. Hegge T, Henderson M, Amalfi A, Bueno RA, Neumeister MW. Scar contractures of the hand. Clin Plast Surg. Oct; 2011 38(4):591-606. [PubMed: 22032588]

2. Upton J, Havlik RJ, Khouri RK. Refinements in hand coverage with microvascular free flaps. Clin Plast Surg. Oct; 1992 19(4):841-57. [PubMed: 1339640] 
3. McGregor IA. Flap reconstruction in hand surgery: the evolution of presently used methods. J Hand Surg Am. Jan; 1979 4(1):1-10. [PubMed: 365927]

4. Rockwell WB, Lister GD. Soft tissue reconstruction. Coverage of hand injuries. Orthop Clin North Am. Jul; 1993 24(3):411-24. [PubMed: 8341516]

5. Giessler GA, Germann G. Soft tissue coverage in devastating hand injuries. Hand Clin. Feb; 2003 19(1):63-71. vi. [PubMed: 12683447]

6. Friedrich JB, Katolik LI, Vedder NB. Soft tissue reconstruction of the hand. J Hand Surg Am. JulAug;2009 34(6):1148-55. [PubMed: 19643296]

7. Gottlieb LJ, Krieger LM. From the reconstructive ladder to the reconstructive elevator. Plast Reconstr Surg. Jun; 1994 93(7):1503-4. [PubMed: 7661898]

8. Maciel-Miranda A, Morris SF, Hallock GG. Local flaps, including pedicled perforator flaps: anatomy, technique, and applications. Plast Reconstr Surg. Jun; 2013 131(6):896e-911e.

9. Foucher G, Boulas HJ, Braga Da Silva J. The use of flaps in the treatment of fingertip injuries. World J Surg. Jul-Aug;1991 15(4):458-62. [PubMed: 1891930]

10. Pederson WC, Lister G. Wolfe SW. Local and Regional Flap Coverage of the HandIn Green's operative hand surgery (6th edition.).

11. Lister G. Local flaps to the hand. Hand Clin. Nov; 1985 1(4):621-40. [PubMed: 3913678]

12. Cormack GC, Lamberty BG. A classification of fasciocutaneous flaps according to their patterns of vascularisation. Br J Plast Surg. Jan; 1984 37(1):80-7. [PubMed: 6692066]

13. McGregor IA, Morgan G. Axial and random pattern flaps. Br J Plast Surg. Jul; 1973 26(3):202-13. [PubMed: 4580012]

14. McGregor IA, Jackson IT. The extended role of the deltopectoral flap. Br. J. Plast. Surg. 1970; 23:173. [PubMed: 4913775]

15. Lamberty BG, Cormack GC. Progress in flap surgery: greater anatomical understanding and increased sophistication in application. World J Surg. Nov-Dec;1990 14(6):776-85. [PubMed: 2256349]

16. Taylor GI, Palmer JH. The vascular territories (angiosomes) of the body: experimental study and clinical applications. Br J Plast Surg. Mar; 1987 40(2):113-41. [PubMed: 3567445]

17. Taylor GI. The angiosomes of the body and their supply to perforator flaps. Clin Plast Surg. Jul; 2003 30(3):331-42. [PubMed: 12916590]

18. Birkbeck DP, Moy OJ. Anatomy of upper extremity skin flaps. Hand Clin. May; 1997 13(2):17587. [PubMed: 9136033]

19. Chasmar, Leslie R. The versatile rhomboid (Limberg) flap. Can J Plast Surg. 2007; 15(2):67-71. Summer. [PubMed: 19554188]

20. Chao JD, Huang JM, Wiedrich TA. Local hand flaps. J Hand Surg Am. Feb; 2001 1(1):25-44.

21. Atasoy E, Ioakimidis E, Kasdan ML, Kutz JE, Kleinert HE. Reconstruction of the amputated finger tip with a triangular volar flap. A new surgical procedure. J Bone Joint Surg Am. Jul; 1970 52(5): 921-6. [PubMed: 4920906]

22. Ramirez MA, Means KR Jr. Digital soft tissue trauma: a concise primer of soft tissue reconstruction of traumatic hand injuries. Iowa Orthop J. 2011; 31:110-20. [PubMed: 22096429]

23. Gatewood A. A plastic repair of finger defects without hospitalization. JAMA. 1926; 87:1479.

24. Flatt AE. The thenar flap. J Bone Joint Surg Br. Feb; 1957 39-B(1):80-5. [PubMed: 13405949]

25. Flatt AE. Minor Hand Injuries. Journal of Bone and Joint Surgery. 1955; 37-B:117. [PubMed: 14353959]

26. Cronin T. The cross finger flap: a new method of repair. Am Surg. 1951; 17:419-425. [PubMed: 14829803]

27. Foucher G, Merle M, Debry R. The reversed de-epithelialized flap. Ann Chir Main. 1982; 1(4): 355-7. [PubMed: 9382633]

28. Weeks, PM.; Wray, RC. Management of Acute Hand Injury. Mosby; St. Louis: 1973.

29. Germann G, Biedermann N, Levin SL. Intrinsic flaps in the hand. Clin Plast Surg. Oct; 2011 38(4): 729-38. [PubMed: 22032596] 
30. Lai CS, Lin SD, Yang CC. The reverse digital artery flap for fingertip reconstruction. Ann Plast Surg. 1989; 22:495-500. [PubMed: 2665613]

31. Earley MJ, Milner RH. Dorsal metacarpal flaps. Br J Plast Surg. Jul; 1987 40(4):333-41. [PubMed: 3620777]

32. Quaba AA, Davison PM. The distally-based dorsal hand flap. Br J Plast Surg. Jan; 1990 43(1):2839. [PubMed: 2310896]

33. Maruyama Y. The reverse dorsal metacarpal flap. Br J Plast Surg. 1990; 43:24-7. [PubMed: 2155682]

34. Pelissier P, Casoli V, Bakhach J, Martin D, Baudet J. Reverse dorsal digital and metacarpal flaps: a review of 27 cases. Plast Reconstr Surg. Jan; 1999 103(1):159-65. [PubMed: 9915177]

35. Massimo DD, et al. Reverse dorsal digital island flap. Plast Reconstr Surg. 1994; 93:552. [PubMed: 8115510]

36. Santa Comba A, et al. Reverse dorsal metacarpal osteocutaneous flaps. Br J Plast Surg. 1997; 50(7):555-8. [PubMed: 9422954]

37. Gregory H, Heitmann C, Germann G. The evolution and refinements of the distally based dorsal metacarpal artery (DMCA) flaps. J Plast Reconstr Aesthet Surg. 2007; 60(7):731-9. [PubMed: 17512811]

38. Sebastin SJ, Mendoza RT, Chong AK, Peng YP, Ono S, Chung KC, Lim AY. Application of the dorsal metacarpal artery perforator flap for resurfacing soft-tissue defects proximal to the fingertip. Plast Reconstr Surg. Sep; 2011 128(3):166e-178e.

39. Bunnell S. Reconstruction of the thumb. Am J Surg. Feb; 1958 95(2):168-72. [PubMed: 13487934]

40. Brunelli F, Vigasio A, Valenti P, Brunelli GR. Arterial anatomy and clinical application of the dorsoulnar flap of the thumb. J Hand Surg Am. Jul; 1999 24(4):803-11. [PubMed: 10447173]

41. Moberg E. Aspects of sensation in reconstructive surgery of the upper extremity. J Bone Joint Surg Am. Jun.1964 46:817-25. [PubMed: 14161094]

42. Foucher G, Braun JB. A new island flap transfer from the dorsum of the index to the thumb. Plast Reconstr Surg. Mar; 1979 63(3):344-9. [PubMed: 368837]

43. Brunelli F. Le lambeau dorso-cubital du pouce. Ann Chir Main. 1993; 12:105-114.

44. Brunelli F, Vigasio A, Valenti P, Brunelli GR. Arterial anatomy and clinical application of the dorsoulnar flap of the thumb. J Hand Surg Am. Jul; 1999 24(4):803-11. [PubMed: 10447173]

45. Terán P, Carnero S, Miranda R, Trillo E, Estefanía M. Refinements in dorsoulnar flap of the thumb: 15 cases. J Hand Surg Am. Aug; 2010 35(8):1356-9. [PubMed: 20684935]

46. Moschella F, Cordova A, Pirrello R, Brunelli F. Anatomic basis for the dorsal radial flap of the thumb: Clinical applications. Surg. Radiol. Anat. 1996; 18:179. [PubMed: 8873330]

47. Moschella F, Cordova A. Reverse homodigital dorsal radial flap of the thumb. Plast Reconstr Surg. Mar; 2006 117(3):920-6. [PubMed: 16525286]

48. Hrabowski M, Kloeters O, Germann G. Reverse homodigital dorsoradial flap for thumb soft tissue reconstruction: surgical technique. J Hand Surg Am. Apr; 2010 35(4):659-62. [PubMed: 20353865] 


\section{Key points}

- When indicated local hand flaps offer excellent coverage of soft-tissue defects that replaces like with like.

- A variety of traditional and non-traditional local hand flaps can be used to cover most of small to moderate size defects of the hand.

- Although routinely used, application of local hand flaps is an evolving field with multiple new flap designs and modifications being described based on the intricate vascular anatomy of the hand.

- Local hand flaps frequently result in optimum functional and aesthetic outcomes and may spare patients and surgeons alike from more complicated methods of soft tissue repair. 

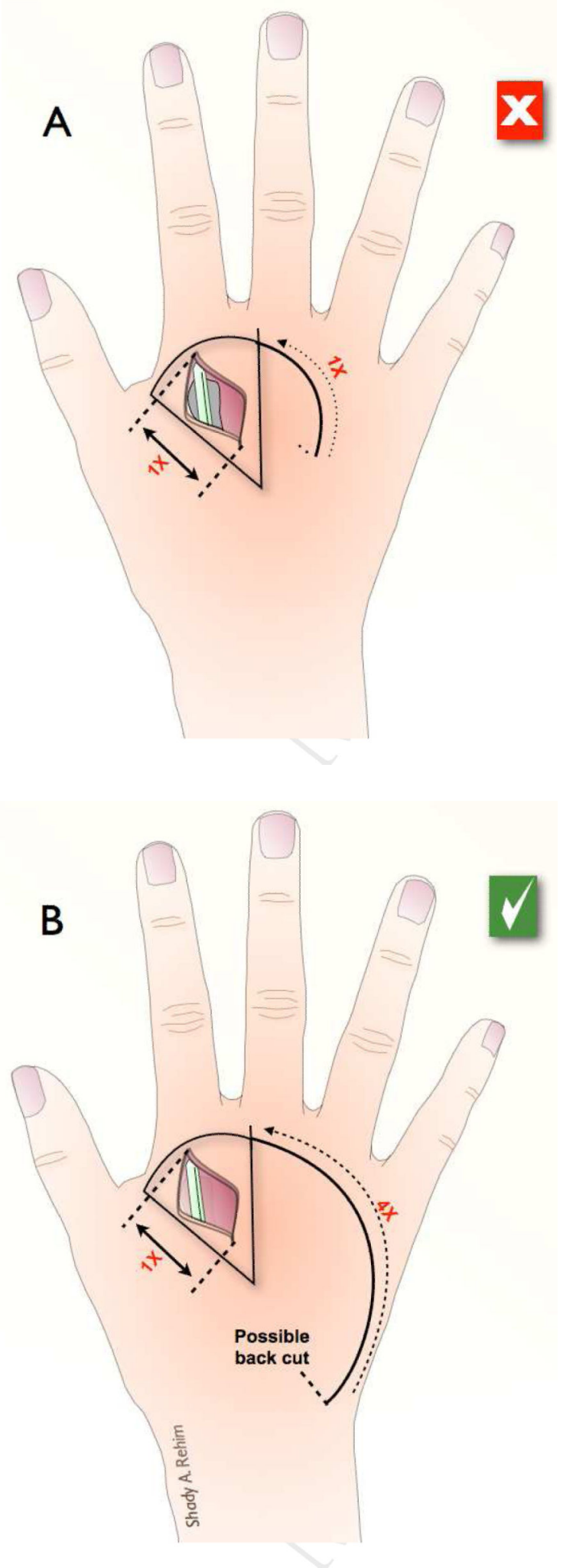

Hand Clin. Author manuscript; available in PMC 2015 May 01. 


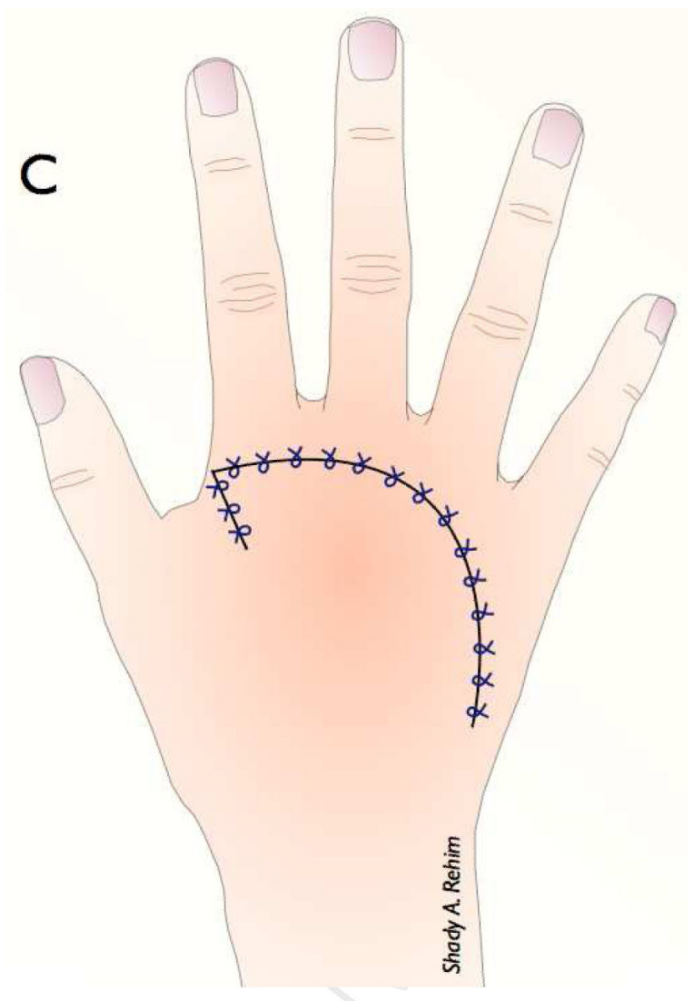

Figure 1.

Demonstrating wrong design of rotation flap (A). Note that the length of the arc of the flap should be at least 3-4 times the diameter of the defect (B) to sufficiently rotate the skin flap into the defect (C). 

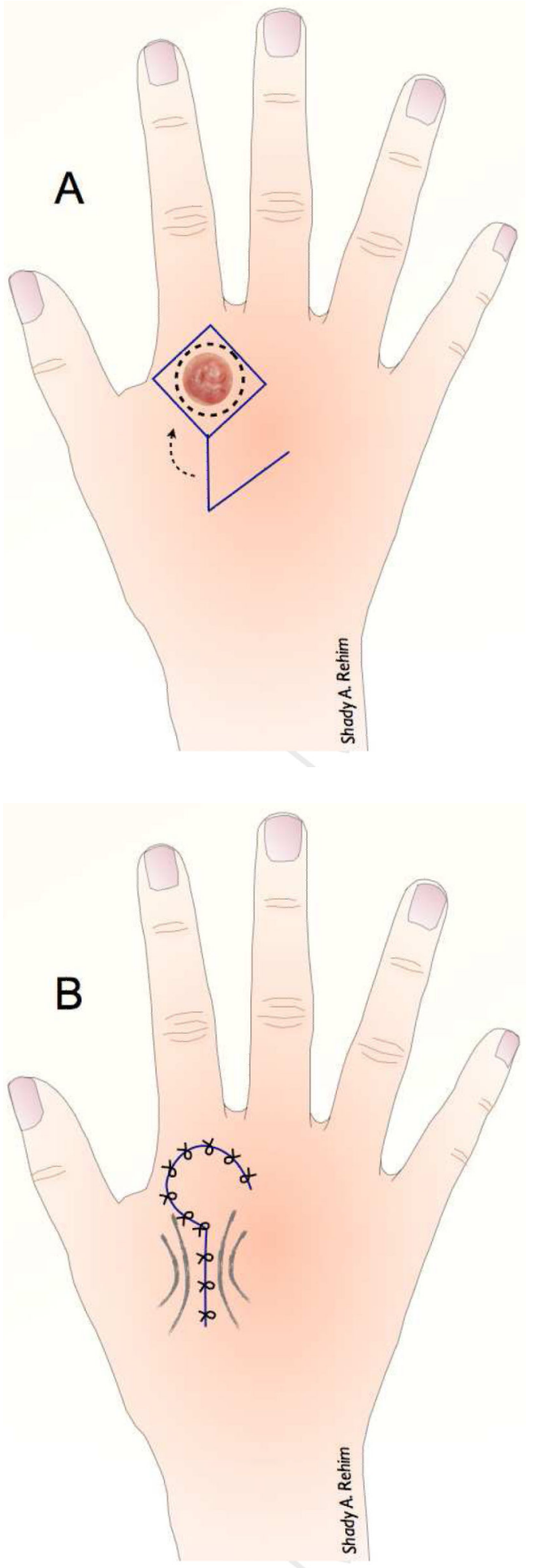

Figure 2.

Hand Clin. Author manuscript; available in PMC 2015 May 01. 
Showing a skin lesion (basal cell carcinoma) on the dorsum of the hand (A) and an outline of rhomboid flap planned for coverage of post-excision skin defect. Note that the line of flap closure should lie within the relaxed skin tension lines to facilitate skin closure taking advantage of the skin laxity (B). Also note that the margins of the transposed flap have been curved or rounded off to avoid strangulation and necrosis of pointed triangular edges of the skin flap. 

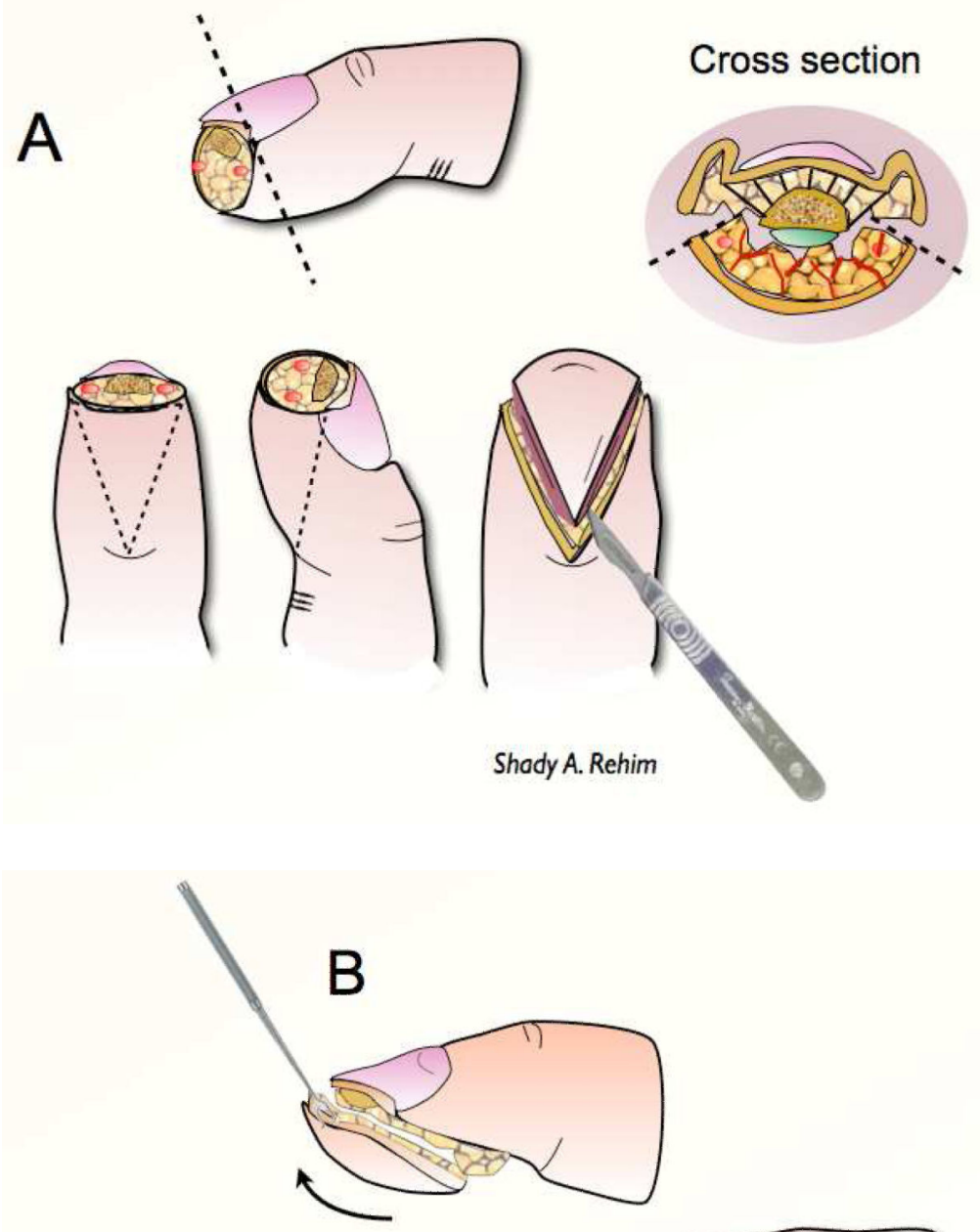

C
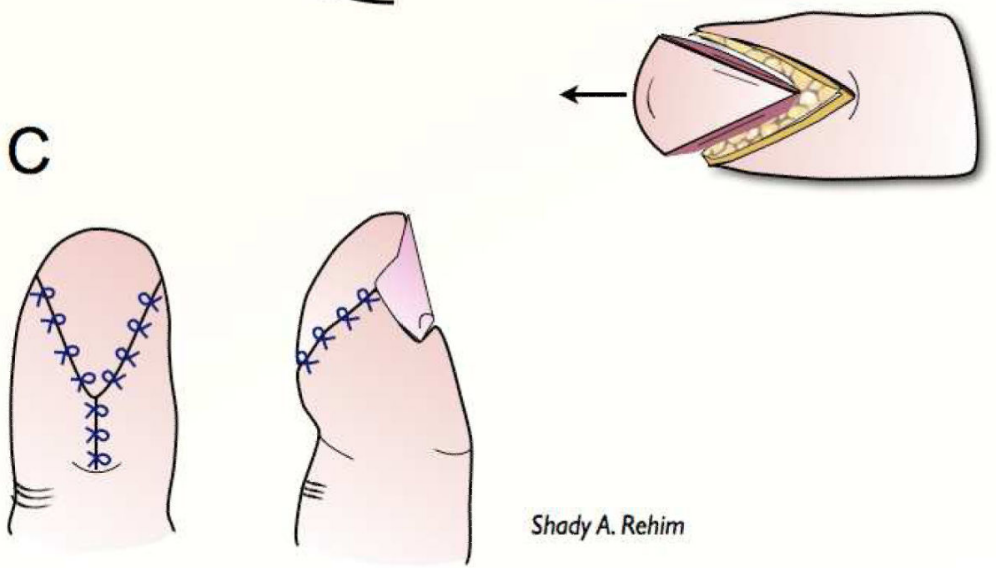

Shady A. Rehim

Figure 3.

Illustrating design of V-Y advancement flap to cover fingertip amputation (A). Note the flap is outlined and dissected off flexor tendon sheath incorporating digital vessels and then advanced to cover the defect (B-C). 


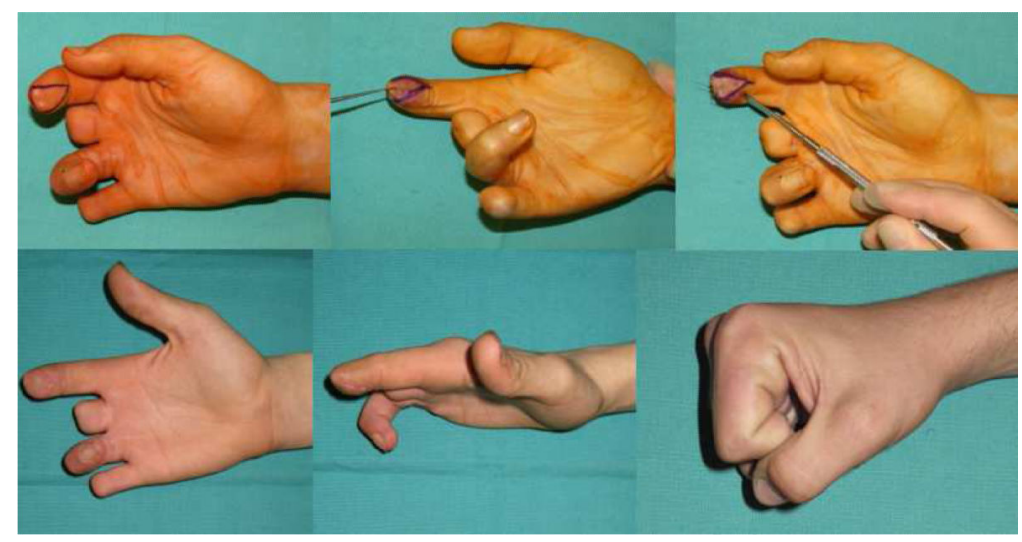

Figure 4.

A V-Y advancement flap was performed to resurface skin of a painful adherent scar resulting from a previous fingertip amputation of the index finger (top). Demonstrating excellent soft-tissue padding, contour, color, texture match and mobility nine months post-operatively (below). 


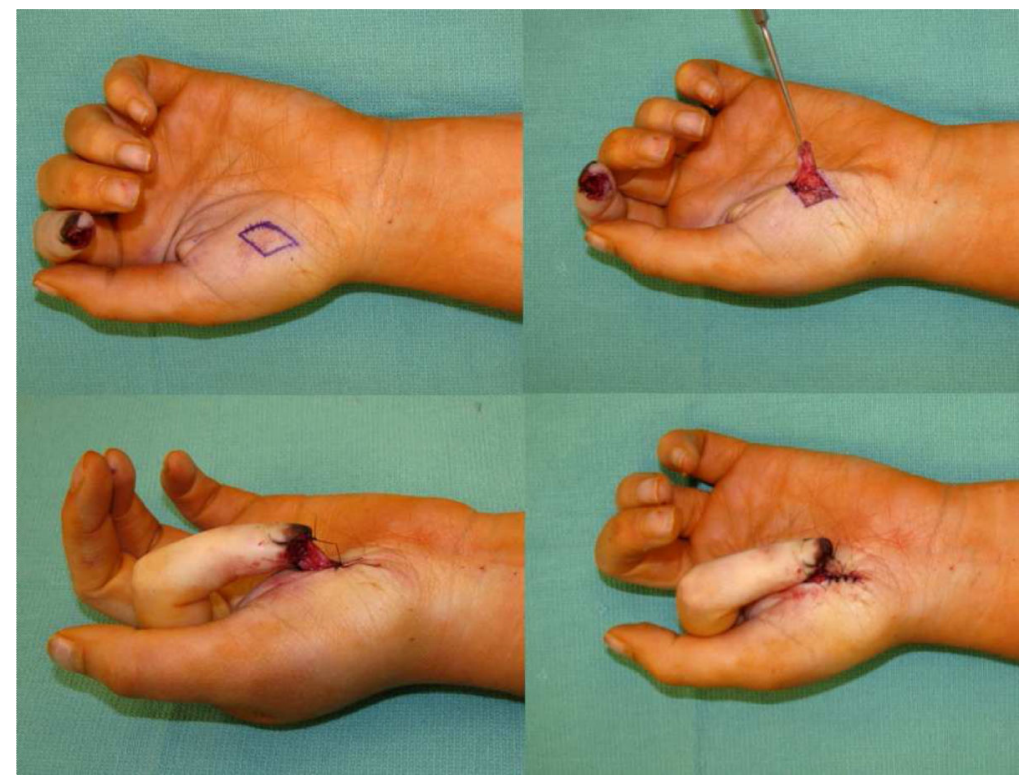

Figure 5.

A 20-year-old female patient who sustained a crush injury to the left index finger with soft tissue loss and necrosis. The necrotic skin was debrided, and thenar flap was then designed to cover the open area. 


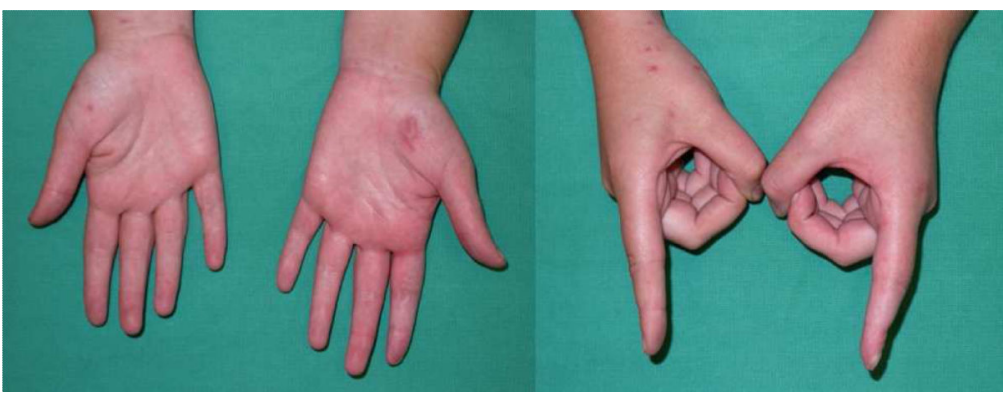

Figure 6.

Showing results soft-tissue replacement of the same patient in figure 4 two months post-operatively. 


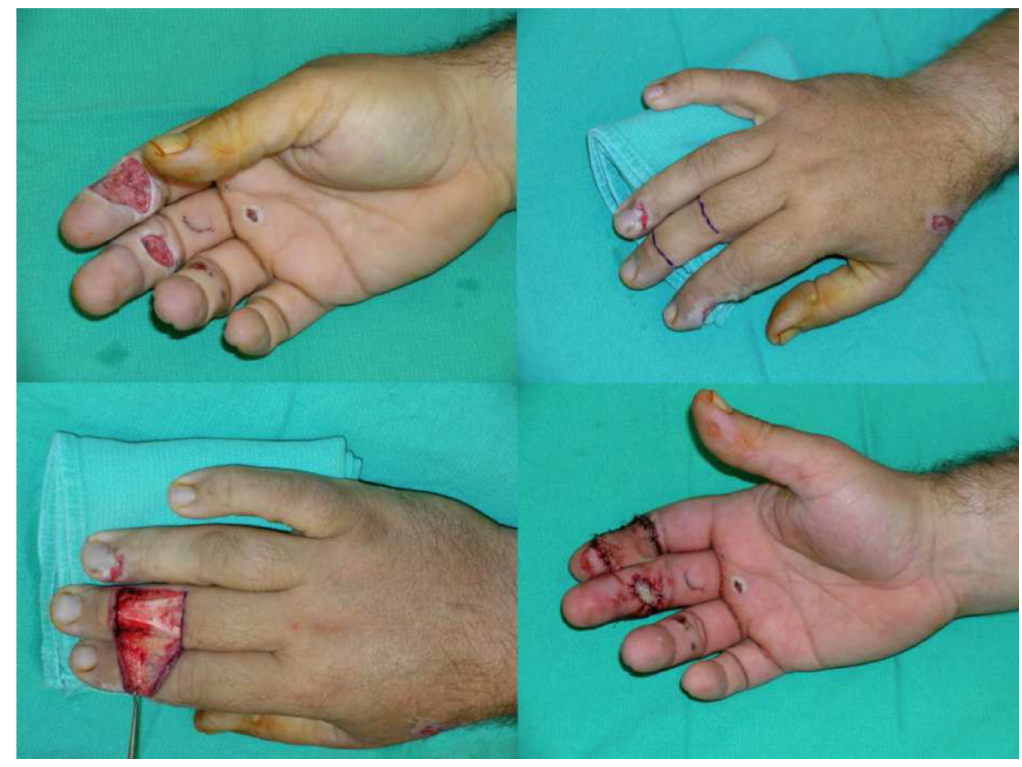

Figure 7.

A 49-year-old who suffered electric burn injury with entrance wound over the index and middle fingers. Following wound debridement the patient had an exposed flexor tendon that was covered with a cross-finger flap obtained from the dorsum of the middle phalanx of the adjacent long finger. 


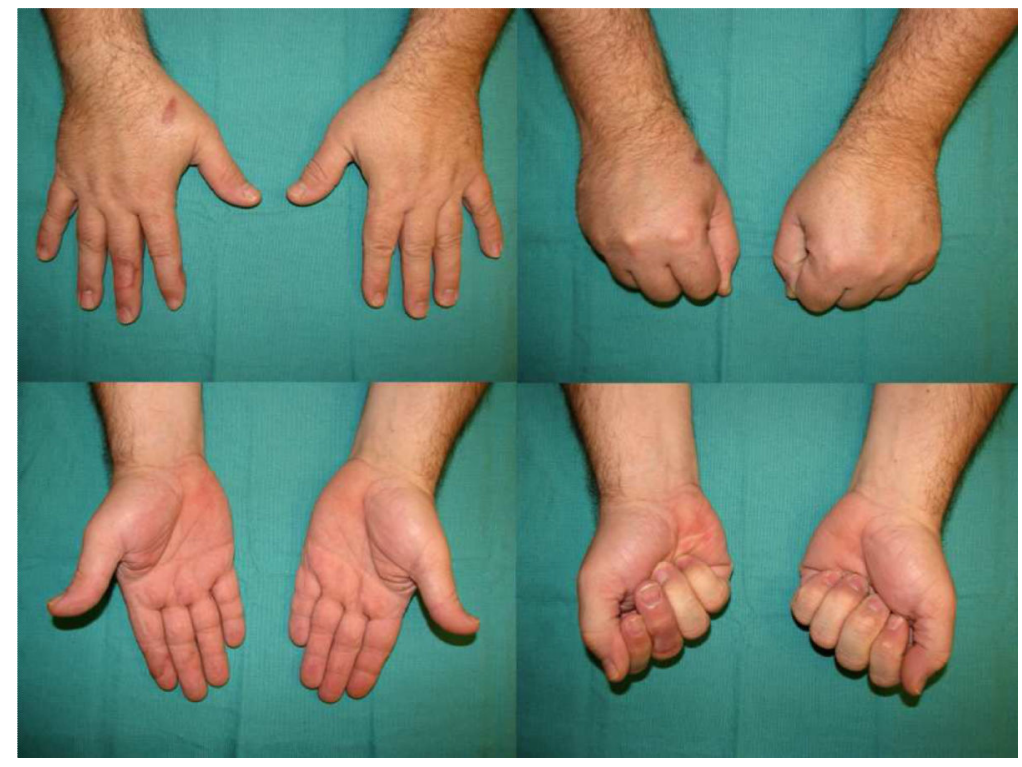

Figure 8.

Showing results soft-tissue replacement with cross-finger flap of the same patient in figure 6 five months post-operatively. 

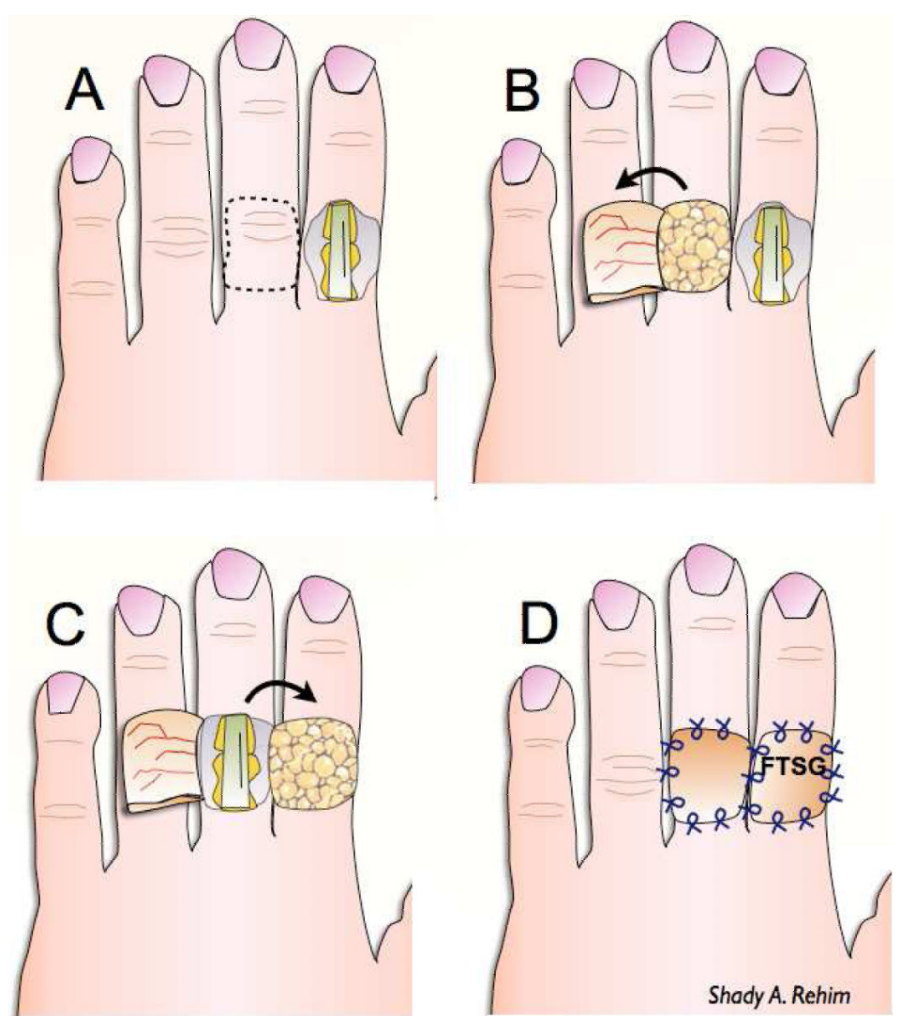

Figure 9.

Illustrating the reverse cross-finger flap. The skin over donor finger is reflected leaving part of deep dermis and subcutaneous tissue that is in turn swung over primary defect and covered with a full-thickness skin graft. Reflecting back the skin that was initially elevated closes the secondary defect created over the donor finger. 


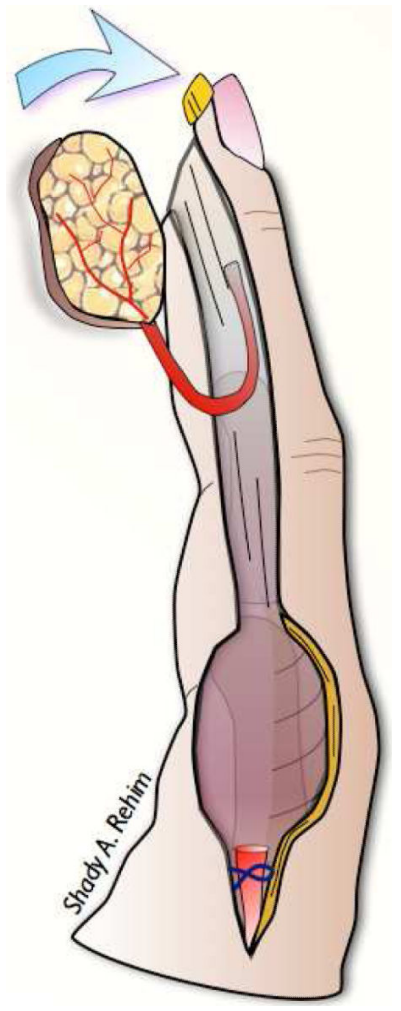

Figure 10.

A reverse homodigital island flap. 


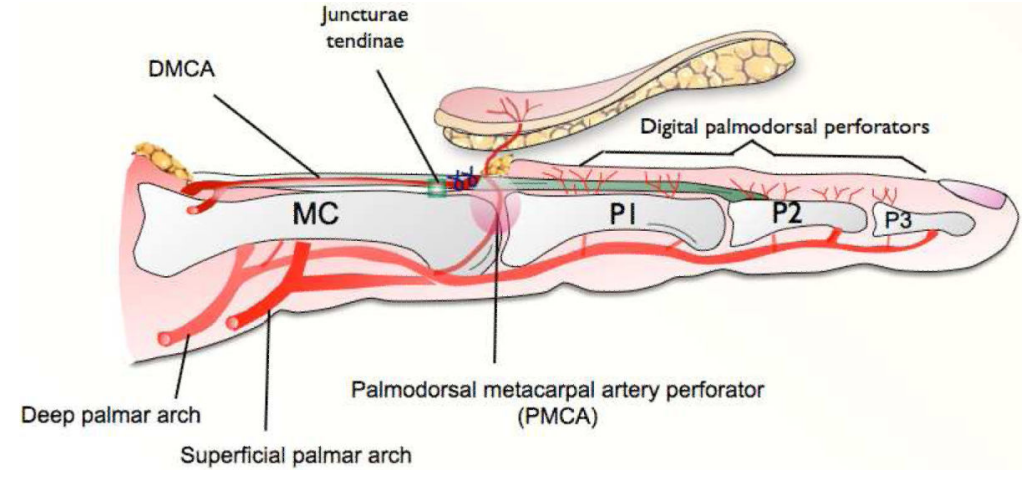

Figure 11.

A schematic illustration of the vascular supply of the distally based DMCA perforator flap as described by Quaba and Davidson. 

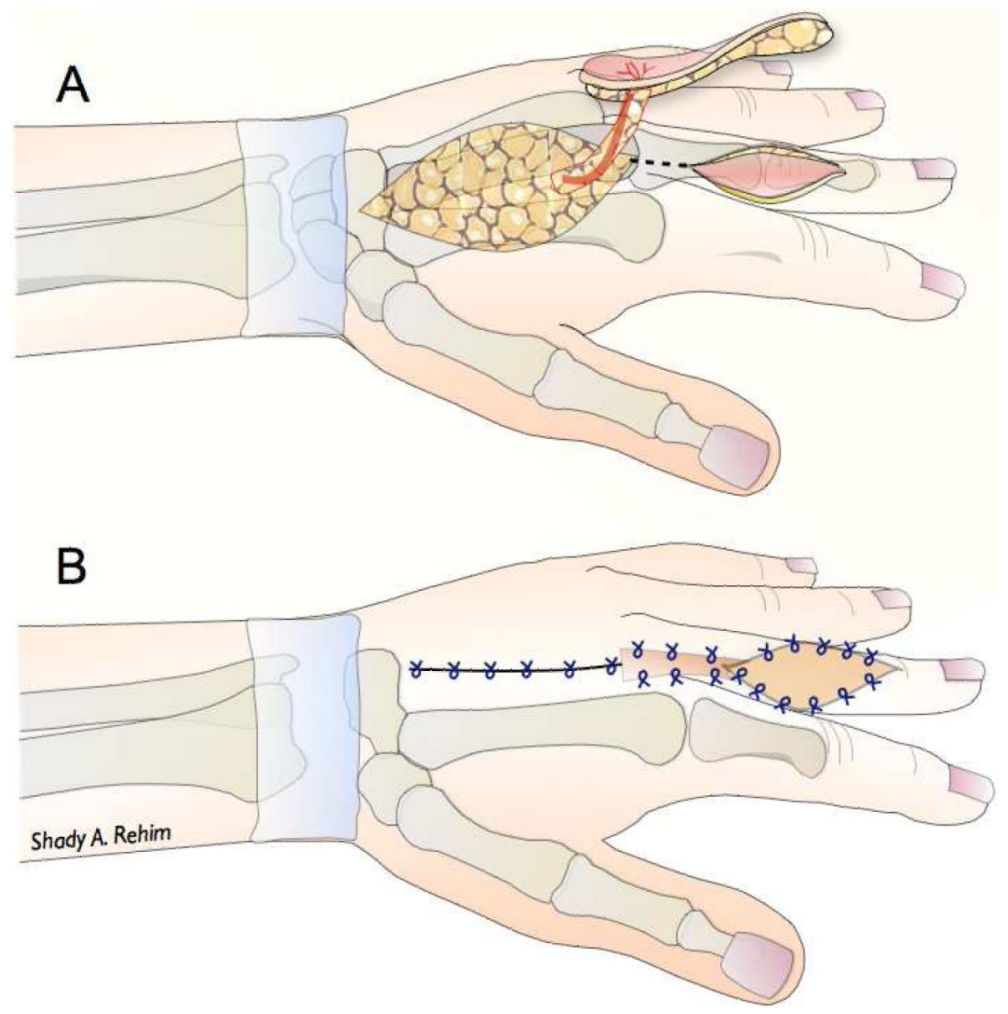

Figure 12.

Demonstrating elevation and inset of dorsal metacarpal artery flap as described by Quaba and Davidson to cover a defect over the dorsum of the finger. 


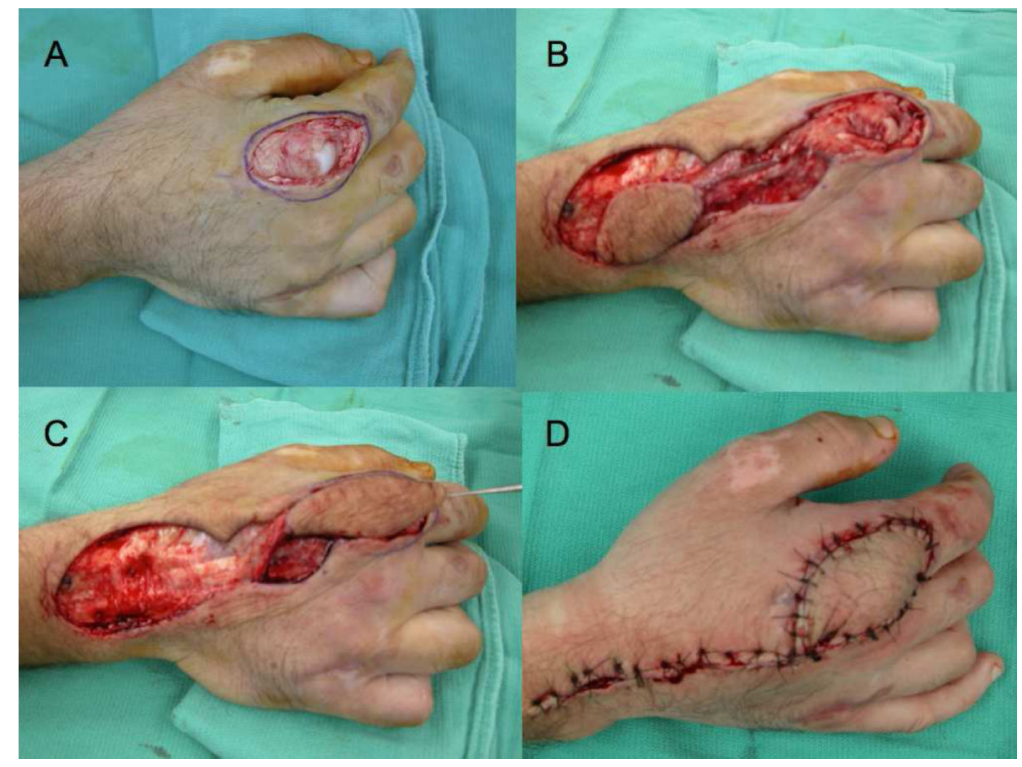

Figure 13.

A 34-year-old male patient who sustained a full-thickness electric burn injury over dorsum of his left index finger (A). Following wound debridement (B) a wound defect measuring $6 \times 3 \mathrm{~cm}$ with an underlying exposed metacarpophalangeal (MCP) joint was created (C). A dorsal metacarpal artery flap was used to cover the wound (D). 


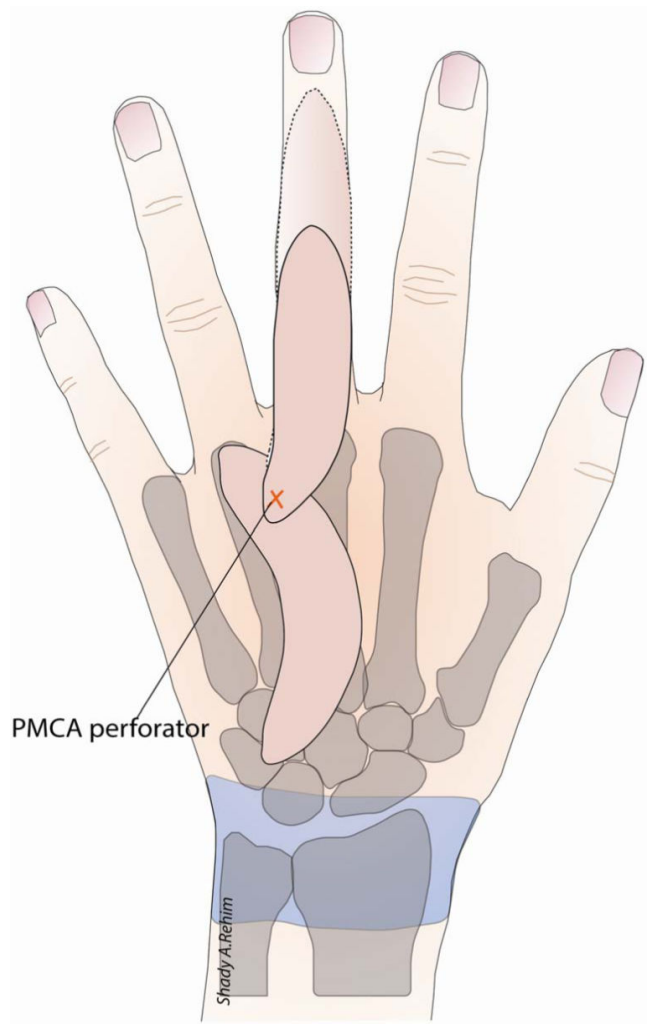

Figure 14.

Demonstrating an ellipse design of the skin paddle of the dorsal metacarpal artery flap, that can be stretched owing to skin elasticity to reach more distant defects on dorsum of the finger. 


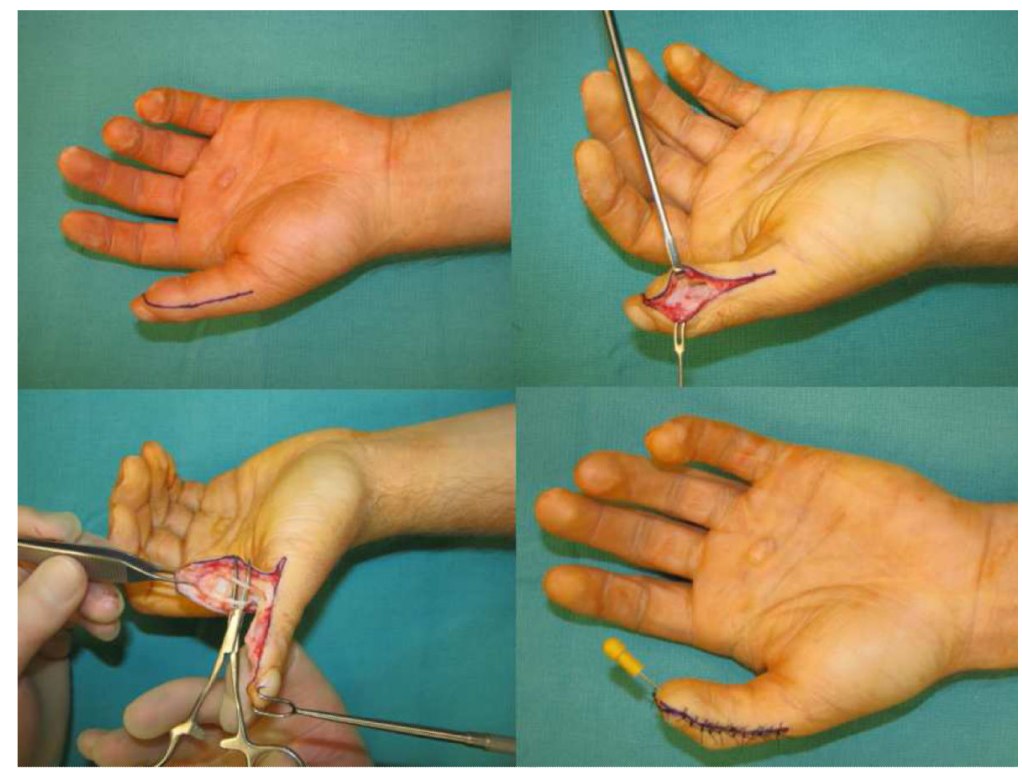

Figure 15.

A 22-year-old male patient who had a crush injury to the left thumb with loss of tissue at the nail bed that was treated initially with primary closure and left him with thin sensitive skin over the tip of the thumb. Following scar excision, a Moberg flap was performed to reconstruct the resultant defect. Note the digital nerves incorporated within the flap (left bottom). 

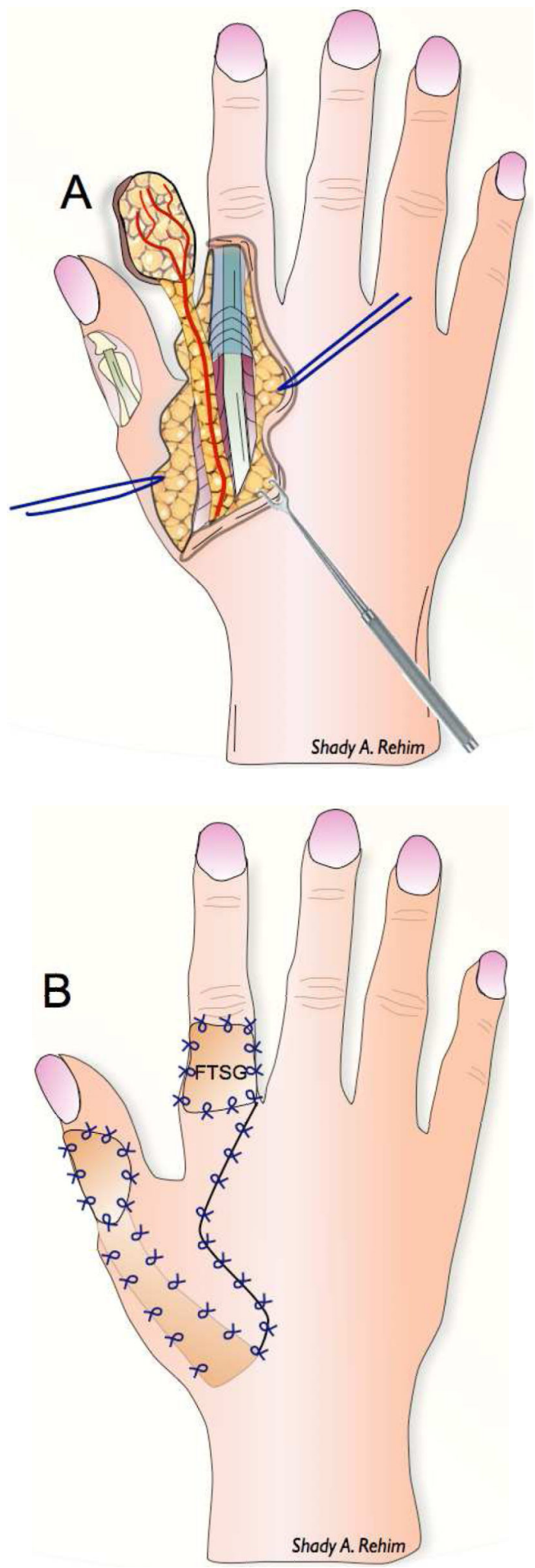

Figure 16.

Illustrating harvesting (A) and transfer (B) of the first dorsal metacarpal artery flap to cover dorsal thumb defect. 

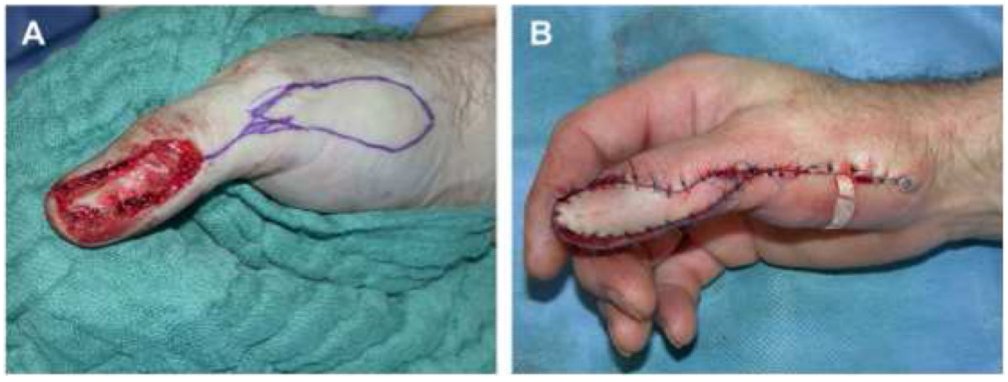

Figure 17.

A dorsoradial thumb defect (A) covered by reverse dorsoradial flap (Moschella flap) of the thumb. The dorsoulnar flap (Brunelli flap) is performed in a similar fashion but elevated from the dorsoulnar side of the thumb (B). (From Germann G, Bidermann $\mathrm{N}$ Levin SL. Intrinsic Flaps in the Hand. Clin Plast Surg. Oct;38(4):729-38; with permission.) 
Table 1

Perioperative considerations

\begin{tabular}{|l|l|}
\hline Wound & $\begin{array}{l}\text { - Size } \\
\text { - Site } \\
\text { - Side (e.g. volar or dorsal) } \\
\text { - Amount \& type of tissue loss (e.g. isolated soft-tissue injury or compound) }\end{array}$ \\
\hline Donor-site & $\begin{array}{l}\text { - Functional loss } \\
\text { - Scar location } \\
\text { - Morbidity }\end{array}$ \\
\hline Flap & $\begin{array}{l}\text { - Texture } \\
\text { - Color } \\
\text { - Volume } \\
\text { - Hairiness } \\
\text { - Sensibility }\end{array}$ \\
\hline Patient & $\begin{array}{l}\text { - Hand dominance } \\
\text { - Age } \\
\text { - Sex } \\
\text { - Occupation } \\
\text { - Medical co-morbidities } \\
- \text { Preferences }\end{array}$ \\
\hline Surgeon & $\begin{array}{l}\text { - Knowledge } \\
\text { - Technical skill } \\
- \text { Preference }\end{array}$ \\
\hline
\end{tabular}

